\title{
ACERCAMIENTO AL ESTUdio de LA TEORÍA DE LA ARGUMENTACIÓN JURÍDICA
}

\section{Serafín Ortiz Ortiz ${ }^{1}$}

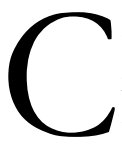

on frecuencia se sostiene que la fundamentación de un fenómeno reside en su construcción histórica. Así, encontrar los fundamentos del derecho implicaría ir a los orígenes de las relaciones sociales y descubrir los primeros comportamientos normados; contemporáneamente, se sostendría también que los fundamentos de la ciencia jurídica se encuentran en las corrientes del pensamiento iniciadoras de la sistematización científica.

En este trabajo, los fundamentos tratan de otro asunto, es decir, no me refiero a la fundamentación teórica, sino a la fundamentación epistemológica: mejor dicho, es el contexto de la teoría del conocimiento jurídico donde se pretende caracterizar los rasgos que particularizan a la argumentación jurídica, la determinación de sus niveles epistemológicos, el estatuto epistemológico al que corresponde la argumentación del derecho, su delimitación y, sobre todo, su especialidad como teoría.

Las primeras reflexiones en el mundo sobre la construcción de una Teoría de la Argumentación Jurídica (TAJ) se formularon hace tres décadas; estas ideas se desarrollaron en principio en el contexto europeo, concretamente en Alemania, donde hace poco más de dos décadas aparecieron los trabajos iniciales para estructurar nuevas construcciones en la teoría del derecho, dando paso así al desarrollo de la TAJ, teniendo

1 Doctor en Derecho por la Universidad Nacional Autónoma de México, y académico de la Universidad Autónoma de Tlaxcala, ex rector de la misma casa de estudios y ex legislador de la entidad tlaxcalteca. Es integrante del Sistema Nacional de Investigadores nivel 2, del Consejo Nacional de Ciencia y Tecnología en México, y miembro honorario de la Real Academia de Jurisprudencia y Legislación Española. 
como referente la primera edición del libro de Robert Alexy, denominado Teoría de la Argumentación Jurídica.

En México, hace apenas una década surgió el interés de incursionar en el estudio de la TAJ. En este contexto, debe señalarse que es el Centro de Investigaciones Jurídico-Políticas (CIJUREP) de la Facultad de Derecho, Ciencias Políticas y Criminología de la Universidad Autónoma de Tlaxcala (UAT), uno de los primeros centros de enseñanza e investigación jurídica en donde se aborda, estudia, estructura y difunde el tema de la Argumentación Jurídica, como disciplina del saber jurídico; es necesario reconocer que en México esta universidad y su posgrado en derecho son «fundadores» de esta disciplina.

Decididos al estudio y desenvolvimiento de esta categoría en la ciencia del derecho, se integró en nuestro plan de estudios de maestría y licenciatura la TAJ, reformándose aquel para incorporar esta materia en 1994, y asimismo, se incluyó una asignatura más para cursarse en el cuarto semestre de la maestría: me refiero, naturalmente, a la Sociología del Derecho.

En la doctrina jurídica, las noticias se conocen no con la oportunidad debida, y ello ocurre igualmente cuando se trata de las reformas legislativas. Es una afirmación acreditada que el derecho tiene un procedimiento de difusión un tanto rebasado con relación a la dinámica social, pues hay reformas, adiciones y/o modificaciones legales que no se socializan en el momento en que entran en vigor, y sólo con el transcurso del tiempo se va tomando conocimiento de esas mismas, y mucho tiempo después el saber jurídico se va sistematizando. Pero en algunos saberes, nosotros hemos querido estar ahí, y este es el caso ocurrido con la TAJ, pues al incorporarse como materia de estudio en nuestro posgrado jurídico, se convierte en punta de lanza en la cultura jurídica mexicana.

La TAJ se construye sobre los cuestionamientos siguientes: en referencia a Alexy, se pueden plantear las siguientes preguntas: “(1) ¿dónde y en qué medida son necesarias valoraciones?, (2) ¿cómo actúan estas valoraciones en los argumentos calificados como «específicamente jurídicos»?, y (3) ¿son racionalmente fundamentables tales valoraciones?”

Agregado a ello, se pueden plantear, además, los siguientes cuestionamientos: ¿cómo deciden los jueces?, ¿de qué manera deciden los jue- 
ces?, y se podría cuestionar también: ¿de qué manera deciden no sólo los jueces en el sentido formal, sino quienes realizan materialmente jurisdicción?, es decir, ¿cómo deciden las autoridades dotadas de poder?

Hay que agregar además, con el mismo Alexy, "cómo pueden ser fundamentados los enunciados, las proposiciones u oraciones normativas..."

Ahora, la TAJ se inició bajo una sola premisa: ¿cómo se resuelven los casos difíciles? Para mejor aclarar este atisbo, podríamos establecer el ejemplo siguiente que, espero, resulte muy ilustrativo: si A y B están disputando la tutela de una criatura o están disputando un bien, y pasa un sujeto, al llamarle le pedimos que decida, entre A y B. ¿Podrá decidir? Creemos que sí, pues decidir es relativamente fácil, cualquiera lo puede hacer. Decidir es algo que comúnmente realizamos, cada día sobre muchas cuestiones; imagínense a los padres de familia que deben decidir entre si el hijo va a una fiesta o va al cine, tienen que hacerlo, ya que, insisto, es un asunto en cierto modo expedito.

En la solución de los problemas jurídicos, decidir también es relativamente fácil. Ahora bien, el problema no reside en decidir, sino en justificar la decisión; es en ese sentido que la TAJ dirime sobre esta disyuntiva: ¿cómo resuelven los jueces los casos difíciles?, y ¿de qué manera justifican esa resolución?; entonces, ¿cómo se justifican las decisiones de los casos?, porque decidir no es lo complicado, como ya dijimos. En materia jurídica acontece igual, si no, entonces ¿qué hacen los señores que integran un jurado que deciden colegiadamente? A veces, en la recreación de la "justicia anglo", miramos a un tribunal integrado por un afroamericano, un blanco, un migrante, un descendiente de migrantes, una ama de casa, un cura, etc., y todos ellos están obligados a decidir, aun cuando no son expertos del derecho; no obstante, deciden, pero el problema de fondo es justificar la decisión que han adoptado; casi todo en la vida es así, pues adoptar una decisión es hacer de ello algo paradigmático. Esto se consigue sólo si se justifica esa decisión.

En ese contexto, es posible afirmar que ahora los jueces tienen más problemas al momento de resolver sobre el conflicto que se les plantea, porque cuando deciden, tienen que justificar su decisión, de tal forma que si hay un imperativo en el texto constitucional que es inamovible, 
entonces las justificaciones de las decisiones judiciales tendrán que ver esencialmente con el respeto a esos principios constitucionales, pues también se debe reconocer que las reformas contemporáneas en materia legislativa afectan la decisión judicial; es decir, se debe considerar que las noticias jurídicas se socializan, en muchas ocasiones, como ya lo mencioné líneas atrás, con cierta tardanza; es una idea coincidente, como ejemplo, con el aspecto normativo, que con toda seguridad el lector ha revisado ya, sobre la reforma a la Constitución Política de los Estados Unidos Mexicanos de fecha 14 de agosto de 2001, al artículo $1^{\circ}$, donde finalmente se asienta un "principio de reserva" para los gobernados, ya de si muy postergado. Nos referimos al principio de reserva del respeto a la dignidad de la persona.

El respeto a la dignidad de la persona humana se ha erigido como un principio inamovible. De este principio parten la mayoría de las constituciones del mundo y conforme a aquel:

Queda prohibida toda discriminación motivada por origen étnico o nacional, el género, la edad, las capacidades diferentes, la condición social, las condiciones de salud, la religión, las opiniones, las preferencias sexuales, el estado civil o cualquier otra que atente contra la dignidad humana y tenga por objeto anular o menoscabar los derechos y libertades de las personas.

En razón de este principio constitucional, nadie puede ser tratado de manera discriminatoria, bajo cualquiera de las diez hipótesis que establece dicha Constitución; por tanto, una decisión judicial debe observar el respeto a los principios y valores constitucionales; sin embargo, justificar estos principios y valores es una labor más difícil, y que en el contexto epistemológico de la TAJ advierte una ponderación axiológica sistemática, formal y científica.

Argumentar significa dar luz, aclarar; etimológicamente viene de las raíces lingüísticas «arguo» (latina) y «argyrus», «argos» (griega). Con estos conceptos se quiere también expresar la idea de: brillar, iluminar, relucir, devienen del mismo «núcleo semántico: resplandor, brillo, blancura». ${ }^{2}$

2 ROJAS AMANDI, Víctor Manuel, Argumentación Jurídica, Edit. Oxford, México, 2010, p. 15. 


\section{Distinción teorética de la TAJ}

Esta es la presentación de un tema tantas veces explorado y exiguamente argumentado.

En 1987 conocí un manuscrito escrito en su idioma original —el italiano- denominado "El derecho penal mínimo", escrito por Luigi Ferrajoli, autor pocas veces referido en la doctrina dominante de la literatura penal.

Con las consabidas dificultades que entrañaba su traducción y a pesar de ellas, muy pronto me involucré en su lectura; a cada renglón que seguía en mi ejercicio analítico, mi sorpresa iba creciendo. ¿Cómo era posible que sucedáneamente, mientras en Latinoamérica estaba yo buscando "los fines de la pena", otro autor en el centro cultural del debate jurídicopenal ya estaba dando razones acerca de la mínima intervención del Estado, y obviamente su fuerza punitiva, frente al comportamiento delictivo? Era inaudito que frente a una "inflación" legislativa penal en México (mas tipos penales, mayor agravamiento de sanciones, uso irracional de la prisión como medio para prevenir el delito, etc.), alguien viniera a plantear, como argumento central, el minimalismo. Es decir, la mínima intervención estatal frente al comportamiento delincuencial, bajo el aforismo de que "El Estado debe conferir el máximo de seguridad para el que no delinque, y el mínimo de violencia para el delincuente". Así se concreta una fórmula de Ferrajoli: "El delincuente frente a su víctima es el más fuerte; sin embargo, frente al Estado, se convierte en el más débil". En esta consideración, se cimenta el imperativo garantista de que el Estado debe respetar los derechos humanos de todos, incluidos los de quien ha cometido un delito, y no hacerlo su víctima.

Pronto descubrí que había otra forma de mirar el mismo problema; no obstante, en el mismo breve manuscrito de nuestro mencionado autor se planteaban otras ideas que agudizaron mi atención: "No se pueden deducir los fines de una institución jurídica —en este caso la pena de prisión- de sus funciones concretas"; esto es, los fines y las funciones de las normas se construyen en estatutos epistemológicos diferentes. 
¡He aquí la clave! Existen niveles epistemológicos en el derecho, a saber: en el nivel superior se sitúan los fines; enseguida, lo establecido en las normas, y en su confrontación ontológica se ubican sus funciones.

Es verdad que con esta lectura de hace más de veinte años, logré disolver muchas dudas, y por lógica me surgieron nuevas preguntas, que se han reproducido desde el surgimiento del positivismo jurídico —el derecho puesto-, a partir del poder de un Estado legislativo de derecho.

Ahora me queda muy claro por qué la gran mayoríaa de los "juristas" salen huyendo de disquisiciones epistemológicas, pues no es de su agrado dialogar acerca de una teoría del conocimiento del derecho, y aun peor, de una Teoría General del Derecho que, siguiendo la tradición kelseniana de la "Teoria pura del Derecho", al jurista, se presupone, sólo le debe interesar el iuspositum, el que deviene del poder estatal, que es el único que tiene validez.

¡Ah, la validez del derecho y sólo su validez interna!

En razón de esta acepción de lo jurídico, del estudio del derecho -legislación, ciencia y jurisprudencia—, se han "desarrollado" sus métodos de conocimiento; desde mediados del siglo XIX los cánones de la interpretación (gramatical, teleológica, sistemática, histórica, etc.), en particular con el imperio de la dogmática jurídica y en la jurisprudencia, en el precedente jurisprudencial (es decir, la manera en que se han resuelto casos anteriores), se suponen como el vector de la decisión judicial. Todo esto sucede en el conocimiento del derecho y ha sido trasladado, prácticamente, a todos los campos y ramas jurídicas; tal es el caso que en el mismo seno de la Teoría General del Derecho todavía no se abandonan los cuatro temas a los que se ha dedicado: el estudio del ordenamiento jurídico (su jerarquía, sus relaciones internas, su coherencia, etc.), las relaciones intersubjetivas que establece (de subordinación, de supra a subordinación, de coordinación), su coercitividad y, desde luego, las consecuencias que acarrea su incumplimiento: la sanción. Asimismo, este enfoque se trasladó a nuevas construcciones normativas, que en los últimos treinta años ha iniciado su sistematización, como lo es el caso de la Teoría de la Argumentación Jurídica, de cuyo constructo me ocupare introductoriamente en las reflexiones que siguen. 
Como se advierte de lo antes expresado, la TAJ, en las tres últimas décadas en el contexto europeo, ha tenido un relativo desarrollo sistemático.

Desde la década de los cincuenta del siglo pasado, diversos autores atribuyen a un conjunto de juristas y filósofos la iniciación de esta teoría. Así, es recurrente referir los nombres de Viehweg, Perelman, Toulmin, a quienes se les asignan trabajos de carácter retórico, tópico, argumentativo; esto es, se les reconoce el mérito de ser pioneros en lo que devendría con el transcurso del tiempo - es decir, la transformación del Estado y el desarrollo social - en lo que hoy conocemos como la argumentación jurídica. Sin embargo, también es recurrente afirmar que el título de la argumentación jurídica se debe al trabajo doctoral de Robert Alexy, cuya tesis fue publicada como una obra de divulgación de ciencia jurídica en el año de 1978.

Circunstancialmente, en otro contexto del mundo — en los Estados Unidos de Norteamérica - otro jurista, recientemente fallecido, Ronald Dworkin, publicaría una obra acerca del mismo objeto de estudio.

En esta trayectoria cronológica, se irían sumando diversas obras, como el caso de Summers, en el contexto norteamericano, y simultáneamente, en Europa surgirían intentos de sistematización de la argumentación jurídica, como de modo emblemático lo desarrolló al inicio de la década de los noventa en España Manuel Atienza, seguido por un buen número de discípulos y seguidores que continuaron este trabajo, como Marina Gascón Abellán y Alfonso García Figueroa. En el mismo contexto español, de idéntica forma pero por su propio ámbito, lo haría el maestro Juan Igartua, del País Vasco, y del mismo modo Josep Joan Moreso I Mateos, en Barcelona; posterior a ellos, una buena cantidad de juristas españoles se interesarían por el objeto de estudio referido.

Recuerdo que en 1994, en una breve estancia en el Instituto Internacional de Sociología Jurídica en Oñati, España, escuché las primeras lecciones acerca de la argumentación jurídica expuestas por Manuel Atienza, de quien recogí sus primeras impresiones, una información panorámica acerca de esta teoría, y en lo sucesivo, sin apartarme del objeto de estudio que desde antes he desarrollado (representado ese objeto por el derecho penal, la política criminal y la criminología), proseguí en la 
búsqueda de más información relacionada con este tema, que considero se ha convertido en el constructo teórico más importante en el conocimiento jurídico, desde la tercera parte del siglo pasado.

Puesto en marcha mi interés por este tema con la literatura de la argumentación a mi alcance, propuse la inclusión de esta asignatura en la licenciatura en Derecho de la Universidad Autónoma de Tlaxcala, y enseguida también en las diversas maestrías que en esta institución se imparten en el Centro de Investigaciones Jurídico-Políticas ya aludido.

$\mathrm{Al}$ principio, el esfuerzo fue personal, y asumí directamente la cátedra con gran dificultad, pero respaldado con una acuciosa lectura, y con la enorme convicción de que esta teoría llegaba para instalarse en el campo del conocimiento jurídico y para transformar la impartición de justicia. Tuve la consciencia, claro está, en considerar la reserva con que advertí el contexto de la "justicia" de los juristas, sin aventurar que esta teoría pudiera resolver los graves problemas que enfrenta la adecuación de la ley a los casos concretos, aunque quizá podría asumirse en ese momento como un portento para conferir mayor certeza a las decisiones de los juzgadores.

Con el transcurso de algunos años, muy pronto comenzaron a publicarse y proliferar en nuestro país un buen número de monografías intituladas como argumentación jurídica, razonamiento jurídico, tópica jurídica, y una diversidad de nombres cuyo eje de estudio era indicativo de la TAJ; sin embargo, con gran desilusión he visto que en todos estos años, estos autores se han dedicado a hacer un "refrito" de la obra de Manuel Atienza, añadiéndole minúsculas aportaciones incoherentes. Tan grave es el caso, que he tenido en mis manos algunas de estas monografías que reseñan, en un par de cuartillas, todas las construcciones teóricas de los autores que he enunciado aquí como pioneros de la argumentación.

Estas razones me han motivado para re-direccionar en México la construcción de la TAJ, es decir, un esfuerzo quizá modesto, pero consciente de que en nuestro país tenemos que hacer un esfuerzo de sistematización más profundo, penetrante, con un andamiaje y/o aparato teorético de mayor densidad, que tenga alcances notables y que guarde un mínimo de coherencia. 
Por ello, he trabajado arduamente en una obra que intitula Fundamentos de la Teoría de la Argumentación Jurídica (Editorial Porrúa, Ciudad de México, ediciones 2014 y 2017), la cual pretende, entre otras cosas, como punto de partida, apartarse de las alegorías de otros escritores connacionales, y acaso, del folclore del que muchos echan mano para subirse al foro de discusión de quienes pretendemos ser argumentistas.

\section{TAJ y Estado constitucional de derecho}

Así, mi propuesta reside en la búsqueda y encuadramiento de la TAJ en un marco epistemológico que delimite bien su contenido, sus alcances, su dimensión histórica, su paralelismo con el proceso de desarrollo social, su advenimiento en un proceso dialéctico de la construcción del conocimiento, su encuadre en un específico modelo político-jurídico que incuestionablemente es donde se incuba esta teoría del conocimiento jurídico. Es innegable que en el desarrollo de la sociedad — si convenimos en que aquel se refunde en el ente Estado-, la teoría aludida tiene un referente específico que, desde ahora adelanto, se vincula a la instauración del Estado constitucional de derecho, acuñado en el mundo a partir de la promulgación de la Constitución alemana de Bonn de 1949, prosiguiéndole la Constitución española de 1978, la Constitución portuguesa de 1976, y otros ordenamientos europeos con las debidas repercusiones en Latinoamérica. Al mismo tiempo, no puede desvincularse que este proceso de transformación socio-política está unido a una nueva concepción del fenómeno jurídico, a la luz de la preocupación de los juristas por la construcción de una epistemología del derecho; dicho de otra forma, es una tarea que tenemos por hacer los juristas: desmontar la vieja concepción de una Teoría General del Derecho, transmutándola por una nueva epistemología.

Enseguida, hay que advertir que el proceso de transformación social nos ha situado en otro escenario del desarrollo de la misma sociedad mundial, y particularmente, es notorio que quienes se ocupan de la revisión de las transformaciones sociales, han fijado su posicionamiento de acuerdo a la percepción que tienen de estas etapas de mutación o metamorfosis del desarrollo de la sociedad. En este punto, recomendaría que a quienes sean partidarios de esta visión reconstructiva de la sociedad, en 
las consabidas etapas de la Antigüedad, la Edad Media y la Edad Moderna, revisen los trabajos de Perry Anderson, de la década de los noventa del siglo pasado, con una carga del revisionismo del materialismo histórico, y para quienes no compartan esta lectura, sería recomendable revisar la construcción de Boaventura de Souza Santos, que tiene una visión diferente inscrita en una perspectiva de una modernidad inconclusa, surgida desde el siglo XVI y que se proyecta hasta nuestros días con el mismo autor. Resultaría interesante revisar también el sentido que para él tiene el derecho y sus justificaciones en el marco de la globalización, particularmente cuando De Souza Santos identifica lo que llama "el consenso del Estado de derecho con la justicia".

Comprendo que los alcances propuestos son un propósito inacabado en el trabajo de mi autoría, y aún estoy incierto en qué medida esa monografía, en una legítima aspiración intelectual, represente panorámicamente el contexto de instauración de la TAJ, para dar luz a aquellos que escriben en el "vacío", atemporalmente, que inclusive confían en prohombres cuyos inventos trascienden los cambios sociales y se convierten en transtemporales.

Ahora, si a ello abona este modesto trabajo, dejo al lector su crítica, que siempre será bienvenida, y asimismo, dejo la reflexión para escribir, siempre en un marco temporo-espacial coherente con el conocimiento que allí se produce.

Es frecuente en los estudios jurídicos asumir conocimientos abistóricos, esto es, que no se inscriben en un contexto temporo-espacial, sino que siguen una suerte de conocimiento lineal que se proyecta del pasado al presente como inalterable y universal, cuestión absolutamente equívoca, porque es incuestionable que cada conocimiento se fragua en un momento específico del desarrollo social.

En virtud de ello, es muy importante para este trabajo tender un hilo conductor que permita generar los fundamentos de una teoría desde una perspectiva no historicista ("las alegorías de la historia", es decir, la citación de fechas y lugares comunes), ni tampoco es pertinente la visión historiográfica ("los héroes de la historia", singularizar personajes como los "creadores" del conocimiento). En todo caso, lo más recomendable es situar la producción del conocimiento en un contexto vinculado a las 
condiciones materiales de existencia de la sociedad, sin que ello implique plegarnos al determinismo económico marxista, sino dotar de un poco de "realismo" a este manuscrito.

Así, podemos convenir que la síntesis de todos los cambios de orden económico, social, cultural y político se refunden en el ente Estado; si esto es así, mi pretensión reside en hacer un bosquejo panorámico, y por ahora, epidérmico, de este fenómeno.

Con el advenimiento de la Edad Moderna, que desde mi perspectiva se inscribe con el surgimiento del Estado liberal de derecho, las condiciones de la sociedad moderna han experimentado un proceso de mutación permanente, más o menos de siglo a siglo. En tal virtud, podemos identificar que a finales del siglo XVIII surgirá este primer modelo de organización jurídico-política en el contexto francés, que devendrá del proceso revolucionario provocado por la repercusión de la Ilustración. Este modelo político tiene sus propias particularidades, ya que fundamenta su existencia en la configuración de ciertos valores que prevalecen hasta el día de hoy, a saber: la libertad, la igualdad, la seguridad y la propiedad privada.

Con el transcurso del tiempo, este proceso mutante sigue su derrotero, y así encontramos que a mediados del siglo XIX se instaurará en el contexto europeo, el llamado modelo de Estado intervencionista, cuyas singularidades se fincan en una mayor injerencia del Estado en la vida colectiva, en esencial en dos horizontes: en el aspecto económico y en el aspecto social, sin desmontar su construcción ideológica de cuño propio, particularmente manipuladora de las clases marginales.

Enseguida, es destacable el advenimiento del Estado benefactor, también llamado Estado social de derecho, cuya raigambre se fundamenta en la Constitución alemana de Weimar, de 1919, y a partir de cuyos dispositivos constitucionales se planteaba en el contexto alemán la satisfacción de las necesidades emergentes de la sociedad, desde esos señalados dispositivos constitucionales que ordenaban al gobierno los deberes positivos de alimentación, vivienda, acceso a la salud, educación y empleo, y con esta prelación lógica, conseguir el bienestar de la mayoría de la población. Este modelo benefactor se extendió por diversas regiones del mundo, en lo que posteriormente se les llamaría países desarrollados, y 
por exclusión, algunos autores motejaron a los demás que no reunieron estos requisitos, como países "subdesarrollados". Tal vez en este punto, sea importante aclarar que resulta menos peyorativo hablar de economías centrales y periféricas antes que magnificar el desarrollismo.

En el siglo XX, surgiría en el ordenamiento de la Constitución de Bonn de 1949 el denominado Estado constitucional de derecho, cuya premisa emblemática como modelo político la constituye "el principio de reserva constitucional" en "la defensa y protección de la dignidad de la persona humana", simbólica y representativa de todos los derechos humanos. Este documento se proyectaría sobre la mayoría de las Constituciones en el mundo occidental, con lo cual vendría la reforma de la Constitución española de 1978, la Constitución portuguesa de 1976, y algunas Constituciones en nuestra región, particularmente la Constitución de Brasil, de Colombia, entre otras.

En este mismo sentido, se reformaría la Constitución Política de los Estados Unidos Mexicanos en su artículo $1^{\circ}$, el 14 de agosto del año 2001 , incluyendo el principio de defensa y protección de la dignidad humana, y tras de él, todos los derechos humanos.

Llegado a este punto, el lector se preguntará si este es un ejercicio de reflexión ocioso, y que en poco abona a la argumentación; sin embargo, esta es la dimensión que considero más sobresaliente para darle ubicación y contexto al surgimiento de la argumentación jurídica en la cultura contemporánea del derecho. Ciertamente, el Estado constitucional de derecho es el modelo en el que se inscribe por diversas razones el surgimiento de la argumentación jurídica, a partir de los siguientes factores.

Con el advenimiento del Estado constitucional de derecho, surgirán también los órganos de autonomía constitucional, que rompen la clásica tripartición de poderes consabida (Ejecutivo, Legislativo y Judicial); asimismo, emergen nuevas facultades para el Poder Judicial, ampliándolas en tal magnitud que lo convierten "en el poder de poderes", porque justo en el Poder Judicial, es el espacio público en donde se resolverán los problemas significativos y relevantes de los poderes públicos.

Como es de advertirse, no sólo el impacto de los derechos humanos, sino las reformas ya referidas, son las que van caracterizando a un modelo político que requiere otro tipo de derecho. $\mathrm{Ya}$ el positivismo no es 
suficiente (el juez no puede seguir siendo la voz del legislador), ahora el juez es un actor dinámico y creativo, y no autómata aplicador de leyes, sino que su deber reside hoy, más que en la interpretación y aplicación de sus decisiones, en ponderar y justificar sus decisiones, ya que convertido en el "poder fuerte", en una democracia del Estado constitucional, está obligado a justificar sus decisiones, y la argumentación jurídica es justamente la teoría que le provee de esos elementos para dar razonamientos y argumentos que satisfagan una decisión democrática, pues de no hacerlo, generaría detrimento a la legalidad y a la constitucionalidad, o bien devendría en agravios a los gobernados.

Estas son las razones por las que este documento debe tomarse como eje metodológico, sin perderse en la bruma de la abundante producción de ideas de los argumentistas contemporáneos, que a menudo esquivan o desconocen que todo conocimiento humano se inscribe en un tiempo y lugar determinado.

\section{Fuentes de información}

ALEXY, Robert, Teoría de la argumentación jurídica. La teoría del discurso racional como teoría de la fundamentación jurídica, Centro de Estudios Políticos y Constitucionales, Madrid, 2007.

Constitución Politica de los Estados Unidos Mexicanos, Secretaría de Servicios Parlamentarios, Cámara de Diputados, H. Congreso de la Unión, Ciudad de México, 2018.

ORTIZ ORTIZ, Serafín, Fundamentos de la Teoría de la Argumentación Jurídica, Editorial Porrúa, Ciudad de México, 2017.

ROJAS AMANDI, Víctor Manuel, Argumentación Jurídica, Editorial Oxford, México, 2010. 